\title{
PROPOS SUR LE “DROIT D'ASILE”
}

\section{Franck MODERNE ${ }^{1}$}

RESUMEN: En la primera parte el autor hace una reflexión sobre la evolución del derecho de asilo, vinculado al nacimiento del Estado moderno, y su aparente contradicción con el concepto de soberanía connatural al Estado, haciendo notar que el concepto no deja de ser objeto de una ambigüedad que oscila entre dos extremos: como un derecho del individuo o como una prerrogativa del monarca. Indica, asimismo, que a pesar de que existe un inicio de "subjetivización" para hacerlo un derecho subjetivo individual, susceptible de ser exigido al Estado incluso a través de la jurisdicción constitucional, los Estados no han perdido el control sobre su otorgamiento en tanto que ejercen una facultad que les es inherente. En la segunda parte examina algunas secuelas contemporáneas de la oscilación del concepto que van desde el rechazo de los Estados a otorgarlo hasta la internacionalización del derecho de asilo. Por una parte los Estados se han resistido a reconocer en el asilo un derecho subjetivo individual; por otra, el derecho de asilo se ha "internacionalizado" en el contexto mundial de la postguerra y en el derecho de las comunidades europeas a través de las convenciones internacionales y de los tratados de carácter regional. El trabajo concluye con un cuestionamiento sobre el futuro incierto del asilo en una Europa que ha ido construyendo acuerdos que limitan en cierta forma los derechos y libertades reconocidos en los tratados y convenciones sobre la materia.
ABSTRACT: In the first part the author reflects on the evolution of the right to asylum, linked to the birth of the Modern State, and its apparent contradiction to the idea of the adaptation of sovereignty to the State, noting that the idea does not cease to be the object of an ambiguity which oscillates between two extremes: as a right of the individual or a prerogative of the monarch. He also notes that despite a commencement of "subjectivism" existing to make this a subjective individual right which can be required from the State, even through Constitutional jurisdiction, States have not lost their control over the granting of same as long as they exercise a power inherent to them. In the second part an examination is made of some aspects of the contemporary aftermath of the oscillations in this concept, ranging from the State's refusal to grant same to the internationalization of the right of asylum. On the one hand States have resisted the recognition of the right of asylum as a subjective individual right; on the other, the right of asylum has become "internationalized" in the postwar period and in the right of the European communities through international conventions and treaties of a regional nature. The work ends with an examination of the uncertain future of asylum in a Europe which has gradually established agreements which, to a certain extent, limit the rights and liberties recognized in the relevant treaties and conventions.

1 Professeur à l'Université de Paris I (Panthéon-Sorbonne) et directeur du Centre de Droit Public Comparé des Etats Européens. 
Les propos qui suivent ont seulement pour objet d'attirer l'attention sur le sort d'un "droit" qui aura quelque difficulté à trouver ses marques dans l'Europe de demain, dans cet "espace de liberté, de sécurité et de justice” qu'évoque l'article 5 du Traité de 1'Union européenne. ${ }^{2}$ Ils poursuivent ce faisant une réflexion que l'auteur avait déjà amorcée, essentiellement à partir du droit constitutionnel, ${ }^{3}$ et qu'il convient aujourd'hui d'élargir au droit d'origine "externe", international ou communautaire.

Le droit d'asile? D'abord est-ce un "droit"? Et qu'en reste-t-il? Ces interrogations désabusées correspondent à l'impression générale qui se traduit de plus en plus fréquemment, avec des tonalités variables selon la sensibilité des observateurs, dans les titres d'ouvrages et d'articles qui se succèdent à un rythme accéléré depuis quelques années. ${ }^{4}$ La présente publication ne fait pas exception, même si elle s'exprime sur ce terrain avec la mesure qui sied aux travaux scientifiques universitaires.

Pourtant l'enjeu est de taille. Le sort de tout droit, attaché à une conception libérale du pouvoir et de ses rapports avec les citoyens, ne saurait laisser indifférents ceux qui accordent quelque crédit au thème de l'Etat de droit (même s'il n'est pas exactement celui que préconisait la doctrine allemande à la fin du siècle dernier) et qui imaginent volontiers que les libertés acquises ne sauraient que progresser grâce à la vigilance tutélaire d'une justice constitutionnelle (ou ordinaire) tout entière tournée vers la protection des droits fondamentaux.

2 H. Labayle, “Un espace de liberté, de sécurité et de justice”, RTDE, 1997, no. 4, p. 813 et s.

3 F. Moderne, Le droit constitutionnel d'asile dans les Etats de l'Union européenne, Economica, 1997.

4 Le vocabulaire utilisé par les auteurs est empreint d'un pessimisme grandissant, résigné ou indigné selon le cas: La crise du droit d'asile (Ph. Ségur, PUF, 1998, Coll. Politique d'aujourd'hui) fait écho à "L'asile politique en question" (M. Bettati, PUF, 1985). De l'ancienne "hospitalité" (plus ou moins généreuse il est vrai) on est passé aux "contrôles migratoires" par nature moins accueillants, dénonce F. Crépeau (Droit d'asile; de l'hospitalité aux contrôles migratoires, Bruxelles, Bruylant/Ed. ULB, 1995). Les doutes récurrents cèdent progressivement la place aux constatations plus réalistes (L. Legoux, La crise de l'asile politique en France, Paris, 1995, Centre français sur la population et le développement; C. Teitgen-Colly, "Le droit d'asile: la fin des illusions", AJDA, 1994, p. 97 et s.; D. Meissner, "The Asylum Crisis", in International Migration Challenges in a New Area, Ed. Commission trilatérale, 1993, p. 49 et s.; G. Noiriel, La tyrannie du national. Le droit d'asile en Europe 1793-1993, Paris, Calmann-Levy, 1991). 
Or le droit d'asile a souffert, tout au long de son histoire tourmentée, des amalgames plus ou moins savamment entretenus, des confusions orientées et des dérives sémantiques qui ont conduit à la capitis deminutio qu'il connaît aujourd'hui dans les Etats de l'Union européenne, quels que soient les artifices de présentation utilisés par les pouvoirs politiques en place.

C'est de cette mutation, souvent subreptice, qu'il convient de rendre compte. Peut-être révèle-t-elle, au-delà des non-dits et des tactiques de camouflage, la force subversive potentielle d'un concept redoutable qui met en rapport direct l'individu demandeur d'asile — touché dans ses droits les plus élémentaires, sa liberté et sa dignité- et l'Etat dont il n'est pas le citoyen, et qui n'entend pas abandonner sa souveraineté territoriale. C'est au nom de la liberté, celle qui appartient à tout homme, que l'asile est sollicité, mais c'est en fonction de sa souveraineté que l'Etat, même s'il estime être un protecteur honnête des droits fondamentaux, veut conserver la maîtrise de la décision d'accueil sur son territoire.

$\mathrm{Au}$ surplus, et comme l'avait fort bien montré L. Bolesta-Koziedbrovs$\mathrm{ki}^{5}$, derrière la pratique étatique du droit d'asile se dessine plus ou moins nettement un conflit de souverainetés entre Etats. ${ }^{6}$ Accorder l'asile à une personne qui estime ne plus pouvoir bénéficier de la protection légitime de son État d'origine, c'est inévitablement admettre (et faire savoir ouvertement) que cet État ne se comporte pas, ou plus, en État de droit. C'est le vouer par là-même, d'une certaine manière, à l'opprobre généralisé des nations démocratiques et des organisations internationales qui s'en veulent le reflet. Ce risque-là n'est pas couru aisément. Il est gros de conséquences politiques.

Eu égard au contexte politico-historique dans lequel il s' est inscrit, ${ }^{7}$ le droit d'asile n'a jamais pu, en définitive, développer ses virtualités et il est plus que douteux qu'il parvienne dans un avenir prévisible à s'affirmer pleinement comme tel.

5 Le droit d'asile, Leyde, 1962, p. 323.

6 O. Beaud, "Propos inactuels sur le droit d'asile: asile et théorie générale de l'État", Les Petites Affiches, 13 oct. 1993, p. 16 et s.

7 V. notamment, les ouvrages de L. Bolesta-Koziedbrodski, de F. Crépeau, de Ph. Ségur, précités; v. aussi, sous l'angle du droit international, Droit d'asile et des réfugiés, Société française pour le droit international, Colloque de Caen, Pedone 1997, avec notamment l'étude introductive de D. Alland, "Le dispositif international du droit de l'asile", p. 13 et s. 
Comment en est-on arrivé là? Plusieurs facteurs y ont contribué. Les confusions sémantiques ne sont que l'expression externe d'amalgames conceptuels autrement pernicieux. Que l'on s'interroge sur la pertinence comparée des expressions "droit d'asile", "droit de l'asile", " "droit à l'asile" démontre a priori que ces vocables ne recouvrent pas la même réalité. Il reste que le vieux "droit d'asile", qui figure expressis verbis dans le Préambule de la Constitution de 1946 (al. 4), conserve la faveur de la très grande majorité des auteurs et se retrouve (avec des sens parfois divergents) dans les textes internationaux qui se sont emparés du problème. On le retiendra donc, quitte à prendre quelque distance, le cas échéant, avec les interprétations qui en sont proposées.

Les ambiguiités récurrentes qui règnent en la matière ont favorisé des dérives dans les politiques actuelles des Etats européens, qui annoncent pour le droit d'asile des lendemains plus difficiles encore.

\section{LES AMBIGUIITÉS RÉCURRENTES: DROIT DE L'INDIVIDU OU PRÉROGATIVE RÉGALIENNE?}

Les équivoques qui pèsent sur le droit d'asile sont souvent dénoncées, parfois avec force, mais elles paraissent tellement enracinées dans le coeur même du problème qu'elles survivent généralement aux tentatives de clarification dans les textes contemporains de droit interne.

Indépendamment même des origines de l'asile ${ }^{10}$ qui plonge ses racines dans le sacré et la sacralisation corrélative de certains lieux de refuge et

8 V. les observations de D. Alland in "Le dispositif international du droit de l'asile", op. cit., p. 15; du même auteur, v. Introduction à Textes du droit de l'asile, Que sais-je, PUF, Paris, 1998, p. 3. L'auteur estime que l'expression "droit de l'asile" est de nature à rendre compte de toutes les questions juridiques appropriées "se posant à l'occasion d'une protection territoriale ou statutaire demandée, accordée, refusée ou remise en cause et présentant un caractère international” (ibidem, p. 3).

9 Cette expression a, selon certains auteurs, une "signification plus forte" que celle de "droit d'asile" (Ph. Ségur, op. cit., p. 96) dans la mesure où elle situerait plus nettement le droit d'asile du côté du demandeur; v. aussi F. Crépeau, Droit d'asile: de l'hospitalité aux contrôles migratoires, Bruylant et Ed. ULB 1995, p. 186 et s.; H. Labayle, V Droit d'asile, in Dictionnaire constitutionnel, PUF, 1992, p. 321 et $\mathrm{s}$.

10 La question de l'asile religieux et de son évolution séculaire fait l'objet d'études attentives in Droit d'asile, devoir d'accueil, Desclée de Brouwer, 1995 (v. notamment J.L. Gazzaniga, "Le droit d'asile religieux, évolution historique", ibidem, p. 77 et s.). V. aussi les études de Ph. Ségur, "Le droit d'asile religieux, un droit moribond?", ibidem, p. 87 et s.; "Réflexions sur l'asile religieux", Les Petites Affiches, 20 sept. 1995, p. 13 et s.; La crise du droit d'asile, op. cit., p. 13 et s.). Ses résurgences contemporaines suscitent des interprétations diverses (v. par ex. O. Beaud, "Propos 
de culte échappant au pouvoir temporel, indépendamment du fondement philosophique du droit d'asile aujourd'hui laïcisé, et réinséré dans la théorie générale de l'État, ${ }^{11}$ l'émergence de ce droit dans les sociétés démocratiques contemporaines ne s'est guère appuyée sur une réflexion théorique qui aurait pu en asseoir la légitimité dans la construction de l'État de droit.

Le "droit d'asile", on le sait, a connu une de ses consécrations les plus anciennes (dans l'ordre politique) et l'une des plus symboliques, dans la célèbre proclamation révolutionnaire de $1793,{ }^{12}$ systématiquement évoquée à cet égard.

Un tel patronage tendait à associer l'asile à l'Etat républicain, désormais "sanctuaire" laïque de tous les étrangers "bannis de leur patrie pour la cause de la liberté" —et surtout à rapprocher l'asile de la revendication libérale individualiste moteur de la dynamique révolutionnaire-.

L'asile devenait ainsi une protection que le nouvel État révolutionnaire s'engageait théoriquement à accorder sur le territoire de la République aux étrangers chassés de leur propre État en raison de leur combat pour la liberté. Il concernait tous les étrangers et s'apparentait ainsi à un droit de l'homme, avec cette réserve que son champ d'application (certes vaste) ne concernait malgré tout qu'une catégorie définie (celle des étrangers); en outre, l'octroi de l'asile relevait plutôt d'une obligation impérieuse de la France, patrie d'accueil, qui se devait d'assumer son rôle historique de terre de liberté. L'image d'une "France, terre d'asile" est liée à cette première approche.

En même temps, mais le paradoxe n'est qu'apparent, l'asile pouvait être regardé comme un véritable "droit" par ses bénéficiaires potentiels. L'expression "droit d'asile" ne figure sans doute pas dans la terminologie constitutionnelle révolutionnaire, mais l'idée d'un droit de l'individu (étranger) susceptible d'être exigé de l'État (français) dans une conjonc-

inactuels sur le droit d'asile: asile et théorie générale de l'État", Les Petites Affiches, 13 oct. 1993, p. 16 et s.; Ph. Ségur, La crise du droit d'asile, op. cit., p. 141 et s.; "L'asile religieux dans la modernité", Migrations, sociétés, septembre 1997, no. 53, p. 61 et s.).

11 On s'est demandé parfois si le droit d'asile pouvait être regardé comme un droit naturel, rapporté à l'individu qui en sollicite le bénéfice. Cette interprétation se heurte bien évidemment à toutes les objections qui accompagnent les tentatives d'explication du droit positif contingent et évolutif par un droit naturel extérieur par essence au système juridique dont il entend rendre compte (sur ce point, Ph. Ségur, op. cit., p. 92 et s.).

12 Constitution du 24 juin 1793, article 120. 
ture historique de lutte contre la tyrannie paraît sous-jacente, dans la mesure où l'on imagine mal l'État d'accueil refuser la demande légitime qui lui serait faite après avoir inscrit sa vocation de terre d'accueil dans l'airain de sa Constitution.

A partir de là, les lignes du paysage se sont quelque peu brouillées: le droit d'asile est-il vraiment devenu un droit de l'individu? le droit d'asile n'est-il qu'un droit de nature "politique"? le droit d'asile engage-t-il vraiment l'État à l'égard des étrangers en quête d'un refuge? On ne saurait dire que ces questions, et quelques autres, aient été clairement posées dans l'histoire post-révolutionnaire, au moins jusqu'à une époque récente.

Un tel dilemme est à notre sens le premier élément du débat, et aussi la première illustration du risque de dérive du droit d'asile vers une autre approche, l'approche internationaliste. ${ }^{13}$ Le droit d'asile, dans la logique historique qui est celle de l'idéologie révolutionnaire, aurait pu se configurer comme droit de l'individu, à caractère subjectif, opposable à l'État qui s'engageait à le respecter. L'évolution ne s'est faite que très partiellement et très épisodiquement en ce sens. L'histoire du droit d'asile est plutôt en définitive celle de sa confiscation et de son instrumentalisation par l'Etat.

\section{A. L'amorce d'une subjectivisation du droit d'asile}

1. On notera d'abord la tardiveté de l'affirmation du droit d'asile comme droit de l'individu dans le pays même qui s'en était fait le chantre historique. Il a fallu attendre la Constitution de 1946 pour qu'au détour d'un alinéa du Préambule de la nouvelle charte républicaine, soit reconnu un droit d'asile digne de ce nom. On en connaît la formulation: "Tout homme persécuté en raison de son action en faveur de la liberté a droit d'asile sur les territoires de la République".

Le souffle révolutionnaire n'est pas complètement éteint. Le combat en faveur de la liberté est toujours exigé comme justification exclusive d'une demande d'asile. C'est bien "tout homme" qui est susceptible d'en bénéficier et non seulement ceux qui sont originaires de territoires ou de zones géographiques déterminés. Quant à la "liberté” et au juste combat

13 V. sur ce point, Le droit constitutionnel d'asile dans les Etats de l'Union européenne, Economica, 1997, p. 22 et s. 
que les étrangers en quête d'asile ont mené en son nom, elle n'est pas autrement définie et l'on peut y voir un vestige de la phraséologie révolutionnaire à vocation universaliste.

Mais l'élément novateur est bien la reconnaissance d'un véritable droit à l'asile, droit qui correspond (sous réserve des preuves à établir) à une obligation corrélative de l'État français. Le droit d'asile est ici devenu un droit à caractère subjectif (au moins dans son essence), donc susceptible d'être revendiqué en justice par son titulaire. C'est là l'apport majeur de la célèbre décision no. 93-325 DC du 13 août $1993^{14}$ dans laquelle le Conseil constitutionnel ancre le droit d'asile du Préambule dans la catégorie des droits fondamentaux ("s'agissant d'un droit fondamental dont la reconnaissance détermine l'exercice par les personnes concernées des libertés et droits reconnus de façon générale aux étrangers résidant sur le territoire par la Constitution, la loi ne peut en réglementer les conditions qu'en vue de le rendre plus effectif ou de le concilier avec d'autres règles ou principes de valeur constitutionnelle") — et en déduit les garanties minimales dues aux demandeurs d'asile sur le territoire national, obligation d'examiner sa situation en tout état de cause, respect des "droits de la défense" au cours du processus d'instruction du dossier de demande d'accueil, octroi des droits et libertés élémentaires reconnus à tout étranger admis à séjourner en France, recours juridictionnels contre les décisions de refus, et caetera-.

Il reste que pendant des décennies, même lorsque l'Etat avait pris la forme d'une République démocratique et libérale, le droit d'asile avait été littéralement escamoté dans la lettre des constitutions françaises. $\mathrm{Ni}$ la IIème ni la IIIème République ne lui avaient accordé une attention soutenue (si ce n'est, pour cette dernière et de manière très sporadique, les manifestations de solidarité humanitaire liées aux déplacements forcés de population au lendemain de la 1ère Guerre mondiale). ${ }^{15}$

14 Rec. Cons. const., p. 224; Grandes décisions du Conseil constitutionnel, $9^{\text {ème }}$ éd., 1997, Dalloz, Paris, no. 46, p. 829, obs. L. Favoreu et L. Philip; RFDA, 1993, p. 871, note B. Genevois; RFDC, 1993, no. 15, p. 583, obs. L. Favoreu; AJDA, 1994, p. 97, étude C. Teitgen-Colly; RD publ. 1994, p. 5, étude F. Luchaire; Administration, janv.-févr. 1994, no. 162, p. 156, note E. Picard; $D r$. soc. 1994, p. 69, note J. J. Dupeyroux et X. Prétot; RGDI publ. 1994, p. 1 et s., note D. Alland; Doc. Réfugiés, 1993, Suppl. au no. 229, p. 1, note F. Julien-Laferrière; Les Petites Affiches, 9 sept. 1994, p. 4 et s., chron. B. Mathieu et M. Verpeaux.

15 R. Baclet-Hainque, Réfugiés et asile politique en France depuis la IIIème République, Thèse droit, Paris II, 1985. 
2. La même conception d'un droit d'asile authentique, en tant que droit de l'individu (étranger) ayant des titres à faire valoir contre l'État d'accueil, se retrouve dans quelques textes constitutionnels de la période contemporaine. ${ }^{16}$ Celui de la Loi fondamentale de la République fédérale d'Allemagne (23 mai 1949) mérite une mention particulière: 1'article 16, al. 2, in fine (dans sa version initiale) disposait que "Les persécutés politiques jouissent du droit d'asile". Une telle rédaction ne supportait ni réserve ni condition. Le droit d'asile appartenant aux "persécutés politiques" était regardé comme directement applicable, s'imposant à tous les pouvoirs publics, au législatif comme à l'exécutif ou au judiciaire; le législateur lui-même ne pouvait donc lui porter aucune atteinte en dehors des limites immanentes (immanente Schranken) résultant de l'existence d'autres droits fondamentaux ou de principes constitutionnels. Une abondante littérature a été consacrée à cette question ${ }^{17}$ qui s'est installée au coeur d'une polémique durable jusqu'à la révision constitutionnelle de 1993.

A ce droit constitutionnel fortement affirmé correspondaient des recours en justice jusqu'au niveau le plus élevé, celui de la Constitution.

Tel est aussi le cas du Portugal (Constitution du 2 avril 1976, modifiée en 1982, 1989, 1992 et 1997) dont la charte fondamentale énonce avec une grande générosité que "le droit d'asile est garanti aux étrangers et aux apatrides persécutés ou gravement menacés de persécution en raison de leurs activités en faveur de la démocratie, de la libération sociale ou nationale, de la paix entre les peuples, de la liberté et des droits de la personne humaine". Il s'agit bien, depuis la révision intervenue en 1982, d'un droit constitutionnellement protégé, placé à cette fin dans le chapitre relatif aux droits et aux libertés et bénéficiant de la garantie maximale, celle du juge constitutionnel, le cas échéant. ${ }^{18}$ Pas plus qu'en Allemagne fédérale, l'exercice de ce droit n'est théoriquement soumis à l'intervention préalable du législateur.

La tonalité de la formulation constitutionnelle est déjà plus discrète si l'on se tourne vers l'Italie. La Constitution du 27 décembre 1947 (article 10, al. 3) reconnaît sans doute le droit d'asile dans des termes qui ont

16 On en trouvera une analyse plus détaillée dans notre ouvrage précité, p. 33 et s.

17 Ibidem, p. 34, note 45.

18 Ibidem, p. 65; V. notamment $O$ asilo em Portugal, Vol. I, Conselho Português para os refugiados, Lisbonne, 1994. 
été interprétés par la doctrine italienne majoritaire comme révélant un droit subjectif individuel assorti de garanties adéquates ${ }^{19}$ mais d'une part elle en limite (relativement) le champ d'application en le subordonnant à l'interdiction de l'exercice effectif, par le demandeur d'asile, des "libertés démocratiques" telles qu'elles sont garanties par la Constitution italienne et, d'autre part, en prévoyant que les conditions de ce droit devront être "fixées par la loi". L'existence d'un "droit subjectif parfait" (dirritto soggetivo perfetto) a malgré tout été identifiée par quelques juridictions, cependant que d'autres, soutenues par divers auteurs, s'en tenaient à un interprétation sensiblement plus réductrice.

En toute hypothèse, c'est l'Espagne qui, dans la liste des pays ayant constitutionnalisé le droit d'asile, se trouve le plus en retrait par rapport à la conception subjectiviste du droit d'asile. L'article 13-4 de la Constitution du 27 décembre 1978 n'y fait qu'une allusion réticente, renvoyant à la loi le soin de définir le champ d'application, les conditions et les modalités d'exercice du droit d'asile. ${ }^{20} \mathrm{Au}$ surplus, ce droit ne bénéficie pas du recours constitutionnel d'amparo qui eût été des plus utiles pour assurer sa protection effective au niveau de la norme fondamentale.

Il y a donc lieu d'afficher un scepticisme persistant devant certaines conclusions doctrinales qui doivent davantage à l'imagination de leurs auteurs qu'à une analyse du droit positif. La constitutionnalisation du droit d'asile en Espagne reste jusqu'à nouvel ordre purement rhétorique. Si droit subjectif il y a, il restera amputé de la garantie essentielle, celle de la juridiction constitutionnelle, qui est jugée indispensable pour la protection des droits dits fondamentaux du Titre I de la charte constitutionnelle.

Cinq Etats: la liste des Etats européens qui ont inscrit le droit d'asile dans leur Constitution est courte, très courte même. C'est déjà là un signe: le droit d'asile comme droit subjectif de l'étranger assimilable à un droit fondamental de la personne humaine, susceptible d'être invoqué contre l'État d'accueil et jouissant des attributs habituels des droits constitutionnellement protégés contre les pouvoirs publics n'est pas, et de loin, une conception partagée dans toutes les démocraties européennes.

19 V. notre ouvrage précité, p. 77 et s. et la bibliographie citée eod. loc., note 210, p. 77 et s.; p. 79 et $\mathrm{s}$.

20 Ibidem, p. 69 et s.; v. la bibliographie, notes 183 et s., p. 70 et s.; en particulier D. Lopez Garrido, El derecho de asilo, Ed. Trotta, Madrid, 1991; D. Blanquer, Asilo político en España: garantías del extranjero y garantías del interés general, Civitas, Madrid, 1997. 
Un rapide coup d'oeil sur les chartes des autres démocraties relevant de la même famille permet de constater les mêmes réticences hors du continent européen. Or ni le degré de démocratie "gouvernante" (comme l'eût dit G. Burdeau), ni la qualité de la protection des droits jugés essentiels ne sont en cause.

Il faut donc en conclure que la perception subjectiviste du droit d'asile n'a pas réussi à s'imposer. Que quelques Etats aient franchi ce pas atteste peut-être que l'effort était envisageable, mais plus sûrement qu'il n'a pas été regardé comme indispensable par les autres. Cela suffit, nous semble-t-il, à fragiliser dès le départ le "droit d'asile" en tant que tel.

Si l'on ajoute que les nouvelles Constitutions (ou les révisions constitutionnelles) qui ont officialisé le droit d'asile datent toutes de l'aprèsguerre et se présentent toutes comme des réactions à des régimes autocratiques antérieurs, on voit que la reconnaissance, au plus haut degré de la hiérarchie des normes, d'un droit d'asile individuel peut aussi être interprétée comme le témoignage d'un certain "activisme" démocratique que les vieilles démocraties européennes n'éprouvaient pas le besoin de reprendre à leur compte. Cela dit, même dans un tel contexte, le droit d'asile n'a pas été accordé à l'étranger en tant qu'étranger. L'asile se mérite et les conditions posées par les chartes constitutionnelles européennes sont là pour le rappeler en tant que de besoin: il faut avoir été "persécuté en raison de son action en faveur de la liberté" (France), "persécuté politique" (Allemagne fédérale), "persécuté ou gravement menacé de persécution" en raison de son activité "en faveur de la démocratie, de la libération sociale ou nationale, de la paix entre les peuples, de la liberté et des droits de la personne humaine" (Portugal) ou se voir interdire dans son propre État "l'exercice effectif des libertés démocratiques garanties par la Constitution italienne" (Italie) (la Constitution espagnole, on l'a dit, s'est bornée à une simple affirmation du droit d'asile sans en définir, même sommairement, les conditions). Chacun de ces termes a un poids spécifique même si la phraséologie utilisée puise manifestement dans des sources communes. Les interprétations jurisprudentielles de la "persécution" ou de la négation, par l'État d'origine, des libertés constitutionnelles essentielles à la démocratie ne seront pas nécessairement établies selon les mêmes critères. Le contenu même de la liberté pour laquelle on combat ou que l'on refuse ne sera pas davantage mesuré d'office à la même aune. 
Tout ceci ne peut que relativiser a priori la portée exacte du droit "subjectif" d'asile.

Enfin, la dimension du droit d'asile constitutionnalisé restait avant tout celle d'un droit de l'individu. Les collectivités, les populations, les minorités en tant que telles n'étaient pas prises en compte. Chacun sait qu'elles posent aujourd'hui des problèmes autrement préoccupants.

\section{B. La récupération par l'État du "droit" d'asile}

L'obligation d'accorder l'asile que les révolutionnaires de 1793 pensaient pouvoir imposer à l'État au nom de l'idéal supérieur de la liberté conférait déjà au "droit d'asile" une connotation politique. Lorsque l'État est devenu le ciment juridique des sociétés politiques organisées, il n'a guère hésité à en faire un "pouvoir" régalien, élément d'une souveraineté proclamée, dont il devait s'assurer la maîtrise sur la scène internationale.

\section{La promotion de l'État comme acteur principal d'une politique d'asile}

Il ne faut pas s'étonner outre-mesure de ce que la timide progression du droit d'asile vers un droit subjectif constitutionnalisé dans certains pays se soit accompagnée en parallèle d'un vaste mouvement de confiscation de ce thème par l'État.

Pas davantage ne convient-il d'imaginer qu'à côté des démocraties ayant accepté d'élever le droit d'asile au rang constitutionnel, d'autres s'en tiendrait à une conception strictement régalienne de ce "droit" placé sous la dépendance exclusive de l'État. Celles des démocraties qui ont fait l'effort de traiter le problème sous l'angle d'un droit subjectif à caractère fondamental ont quand même développé une conception étatisée de l'asile comme pouvoir de l'État souverain, au risque de contradictions difficiles à surmonter.

En fait, lorsque les Etats européens se sont constitués ou consolidés tout au long des XIXème et XXème siècles, le thème de la souveraineté territoriale de l'État s'est fortifié corrélativement —et il est devenu une des composantes majeures sur la scène politique. Les sociétés politiques étatisées ont construit dans l'abstraction une entité dont on pouvait imaginer qu'elle n'abandonnerait pas aisément une parcelle de son pouvoir.

L'État disposant par définition de la souveraineté territoriale, le "droit d'asile" pouvait-il lui échapper? Très tôt, en même temps que certaines 
constitutions affirmaient un droit d'asile résolument subjectif, la doctrine internationaliste soutenait volontiers que l'État restait libre de ses décisions en la matière, ${ }^{21}$ ce qui comportait la négation d'un droit subjectif individuel dont l'Etat serait débiteur.

La démarche assurant le primat de la souveraineté étatique sur toute autre considération transparaît avec les déclarations internationales ayant fait place au droit d'asile; leur rédaction passablement embarrassé témoigne du refus des Etats signataires de s'engager dans la voie d'une réduction, même symbolique, de leur pouvoir souverain. Que l'on relise la Déclaration Universelle des droits de l'homme: "22 "Devant la persécution toute personne a le droit de chercher asile et de bénéficier de l'asile en d'autres pays" (article 14): on voit bien que les victimes des persécutions ne disposent d'aucun droit subjectif à obtenir l'asile, que celui-ci leur sera éventuellement octroyé par l'État d'accueil dans l'exercice de sa pleine souveraineté. Au surplus, la version initiale du projet soumis à l'Assemblée Générale de l'ONU avait prévu le droit à ce que "l'asile soit accordé" aux persécutés, ce qui souligne le refus des Etats de retenir la version la plus favorable aux demandeurs d'asile. ${ }^{23}$

La Déclaration de la même Assemblée générale votée le 14 décembre 1967 et portant précisément sur l'asile territorial marque-t-elle un progrès sur ce terrain? Bien au contraire: selon son article 1er, "L'asile accordé par un État, dans l'exercice de sa souveraineté, à des personnes fondées à invoquer l'article 14 de la Déclaration universelle des droits de l'homme... doit être respecté par les autres Etats... Il appartient à l'État qui accorde asile de qualifier les causes qui le motivent". Il est clair que le pouvoir d'accorder l'asile n'est qu'un attribut de la souveraineté des Etats et que ceux-ci sont maîtres des justifications (s'ils daignent les exprimer) qui fondent leurs décisions. Tout au plus la Déclaration de 1967 recommande-t-elle de ne pas considérer l'octroi de l'asile comme un acte inamical à l'égard de l'État d'origine, mais plutôt comme un acte "pacifique et humanitaire".

21 La théorie de Morgenstern est souvent rappelée à ce propos (v. S. Goodwin-Gill, The Refugees in international Law, Clarendon Press, Oxford, $2^{\mathrm{ème}}$ éd., 1996; v. également Le droit constitutionnel d'asile dans les Etats de l'Union européenne, op. cit., p. 24 et s.; Ph. Ségur, La crise du droit d'asile, op. cit., p. 117 et s.).

22 Résolution 217 (III) de l'Assemblée générale des Nations Unies du 10 décembre 1948.

23 F. Crépeau, op. cit., p. 142; G. Goodwin-Gill, The Refugees in international Law, Clarendon Press, 1996 ( $2^{\text {ème }}$ éd.). 
Tout ceci traduit l'impuissance manifeste des organisations internationales (à commencer par la première d'entre elles) à faire du droit d'asile un droit de l'individu opposable aux Etats. Le Pacte des Nations-Unies relatif aux droits civils et politiques du 19 décembre 1966 (qui comportait des engagements plus précis des Etats signataires) se garde bien d'évoquer le droit d'asile dans ses dispositions sur les étrangers (article 13). La célèbre Convention de Genève du 28 juillet 1951 elle-même, dont on aura à reparler, n'est en rien une convention sur le droit d'asile, ${ }^{24}$ même si c'est sous son égide que les Etats européens entendent aujourd'hui traiter le "droit d'asile" indûment absorbé par le texte international. La meilleure preuve, s'il en faut vraiment une, est que, pour combler cette lacune, la Conférence des Nations-Unies de Genève avait (piteusement) tenté de mettre au point un projet de convention internationale sur l'asile territorial, sur la base d'un projet élaboré à Bellagio en 1972, avant de déclarer forfait. ${ }^{25}$ Et pourtant ce projet avait déjà renoncé à invoquer un quelconque droit subjectif des demandeurs d'asile à l'encontre des Etats d'accueil potentiels.

L'État étant devenu un partenaire obligé dans la relation née de la recherche d'un asile, il a détourné à son profit la prérogative d'asile, inséparable à ses yeux de la souveraineté. Ce n'est plus le "peuple" comme au temps de la Constitution de 1793, mais bien l'État qui gère le pouvoir d'accorder ou de refuser l'asile. L'image d'un "droit d'asile" n'est maintenue dans le vocabulaire international contemporain que sous cette réserve implicite. Conformément à une opinion déjà amorcée par $\mathrm{S}$. Pufendorf $^{26}$ et reprise par Ch. Wolff ${ }^{27}$ ou E. de Vattel, ${ }^{28}$ le droit d'asile,

24 V., sur tous ces points, notre ouvrage précité, p. 25 et s. et la bibliographie citée; D. Alland, "Le dispositif international du droit de l'asile", in Droit d'asile et des réfugiés, Pédone, Paris, 1997, p. 13 et s., not. p. 34 et s.; F. Tiberghien, La protection des réfugiés en France, $2^{\mathrm{ème}}$ éd., Economica-PUAM 1988; A. Gralh-Madsen, The status of Refugees in International Law, Sijthoff, Leyde, 1966-1972 (2 vol.); Les réfugiés en France et en Europe, Colloque OFPRA, ronéo, 1994; D. Alland, V "Asile", in Répertoire de droit international, Dalloz, 1998; M. Garcia-Mora, International Law and Asylum as a Human Right, Washington, Public Affairs Press, 1956, p. 26 et s.

25 F. Leduc, "L'asile territorial et la Conférence des Nations Unies de Genève, janvier 1977", AFDI, 1977, p. 221 et s.

26 S. Pufendorf, Le droit de la nature et des gens, trad. J. Barbeyrac (1732), Presses Univ. Caen 1987, 2 vol., Livre III, ch. III, 1 X et s.

27 Chr. Wolff, Principes du droit de la nature et des gens, trad. Formey (1758), Presses Univ. Caen, 1988, 3 vol., Livre IX, ch. II, XXI.

28 E. de Vattel, Le droit des gens ou principes de la loi naturelle appliqués à la conduite et aux affaires des nations et des souverains (1758), Clarendon Press, 1916, Vol. I, ch. XIX, 223 et s. 
mué en pouvoir de l'État, est mis à la disposition de ce dernier pour un usage qu'il détermine comme il l'entend. ${ }^{29}$

\section{De cette évolution, il convient de tirer quelques enseignements}

Le premier, et sans doute le plus important, est que les termes du rapport entre le demandeur d'asile et l'État qu'il sollicite sont radicalement inversés. L'asile n'est plus un droit que l'intéressé pourrait faire valoir contre l'État tenu par un devoir d'accueil, c'est une faveur qui lui sera accordée ou refusée, selon des critères définis unilatéralement (ou, par convention, librement négociés) par ce dernier.

L'expression “droit d'asile”, lorsqu' elle est employée dans un tel contexte conceptuel, n'a pratiquement plus de sens propre. Il s'agit d'un pseudo-droit d'asile, du droit de demander l'asile et rien d'autre. Du côté de l'État concerné, plus que d'un "droit" lui appartenant, c'est bien d'un pouvoir, d'une prérogative régalienne ordinaire, relevant de la souveraineté territoriale la plus banale, qu'il conviendrait de retenir l'image. Continuer à utiliser des termes impropres ne peut qu'entretenir l'équivoque.

Le rôle particulier de l'État, par ailleurs, est souligné dans ceux des systèmes qui ont pourtant constitutionnalisé le droit d'asile comme droit de l'individu. Il est symptomatique par exemple que, dans sa décision no. 93-325 DC du 13 août $1993,{ }^{30}$ le Conseil constitutionnel français a estimé que les dispositions du projet de loi prévoyant des hypothèses de non-admission des demandeurs d'asile "ne font pas obstacle au droit souverain de l'État d'accorder l'asile à toute personne qui se trouverait néanmoins dans l'un des cas mentionnés aux 1 et 4 du présent article". Il est non moins topique que la révision constitutionnelle du 25 novembre 1993, entreprise pour neutraliser la décision no. 93-325 DC, précitée, en ce qu'elle compromettait la mise en oeuvre de la Convention d'application de l'Accord de Schengen (le droit constitutionnel d'asile dont sont titulaires "les combattants de la liberté", aux termes de l'alinéa 4 du Préambule de 1946, avait été réservé par le juge constitutionnel), ait inscrit dans la Constitution un article 53-1, al. 2, dont le libellé reprend, mais au profit de l'État, celui de l'alinéa 4 ("Même si la demande n'entre

29 V. les développements consacrés à ce thème par L. Bolesta-Kozierbrodski, Le droit d'asile, Sijthoff, Leyden, 1962, p. 19 et s.; D. Alland, op. cit., p. 23.

30 V. supra, note 14. 
pas dans leur compétence..., les autorités de la République ont toujours le droit de donner asile à tout étranger persécuté en raison de son action en faveur de la liberté...") et en étend même le champ virtuel à tout étranger "qui sollicite la protection de la France pour un autre motif". Cette modalité de l'asile régalien est regardée comme inhérente à la conception même de l'asile, prérogative de l'État, maître sur son territoire.

On retrouverait aisément, dans les textes organisant le droit d'asile en tant que droit constitutionnel dans les rares pays européens qui lui ont assuré cette promotion, des expressions révélant la présence pesante et insistante de l'État.

Ainsi, au Portugal et en dépit de la volonté clairement affichée du constituant (article 33-6 de la Constitution révisée de 1976), la loi du 29 septembre 1993 pris pour l'application des dispositions constitutionnelles sur le droit d'asile laisse à l'État le pouvoir d'accorder ou de refuser l'asile —et ajoute (article 4-2) que "l'asile peut être refusé si la sécurité externe ou la sécurité interne le justifie ou si la protection de la population l'exige, notamment en raison de la situation sociale ou économique du pays" - ce qui revient à refermer quasi-immédiatement une porte qui paraissait largement ouverte. ${ }^{32}$ En Italie, en Allemagne fédérale, en Espagne comme en France et au Portugal, les organismes qui traitent des demandes d'asile dépendent directement, et étroitement, de l'État ${ }^{33}$ dont le pouvoir de décision est parfois discrétionnairement réservé. ${ }^{34}$

31 Sur les interprétations qu'il convient de donner à cette formulation, v. D. Alland, op. cit., p. 62; F. Moderne, op. cit., p. 57 et s.; C. Teitgen-Colly, "Le droit d'asile: la fin des illusions", AJDA 1994, p. 97 et s.

32 Vital Moreira, "O direito de asilo entre a Constituição e a lei", in $O$ asilo em Portugal, op. cit., vol. I, p. 73 et s.

33 Notons que la participation du Haut Commissariat des Réfugiés des Nations Unies à chacune des sections de la Commission de recours des réfugiés qui, en France, est la juridiction chargée d'examiner les recours contre les décisions de l'Office français de protection des réfugiés et apatrides, n'a pas été jugée contraire à la Constitution (décis. Cons. const. no. 98-399 DC du 5 mai 1998, JO 12 mai, p. 7092; RFDC 1998, no. 35, p. 634, note A. Gaïa; RD publ. 1998, p. 1015, étude F. Luchaire; AJDA 1998, p. 922, chron. C. Teitgen-Colly et F. Julien-Laferrière).

34 V. par ex. l'article $1^{\mathrm{er}}$ de la loi no. 9/1994 (Espagne): "le droit de demander l'asile est reconnu aux étrangers"; il est vrai que, selon certains auteurs, le contrôle exercé par le juge administratif sur la base du nouveau texte (qui modifie une loi antérieure no. 5/1984 du 26 mai 1984), gommerait pratiquement le caractère discrétionnaire du pouvoir étatique (D. Blanquer, Asilo político en España, op. cit., p. 172 et s.); mais cette analyse ne fait pas l'unanimité. 
Les instruments internationaux ne sont pas en reste: outre la Convention de Genève elle-même qui, dans son article 5, énonce qu'elle ne saurait porter atteinte, en aucune de ses dispositions, "aux autres droits et avantages accordés, indépendamment de cette Convention, aux réfugiés" (principe qui vaut a priori pour les demandeurs d'asile proprement dits), la Convention d'application de l'Accord de Schengen du 19 juin 1990 (article 29-4), tout comme la Convention de Dublin du 15 juin 1990 relative à la détermination de l'État responsable de l'examen d'une demande d'asile présentée dans l'un des Etats membres de l'Union européenne (article 9) se réfèrent à la souveraineté de chaque État en matière d'“asile" (au sens qu'elles confèrent à ce terme, v. infra).

Que l'État soit devenu (paradoxalement) le titulaire d'un “droit" dont il use à son gré et dont il fera bénéficier éventuellement les demandeurs d'asile ne paraît pas dépendre des diverses catégories ou formes d'asile recensées par les juristes. L'asile "territorial" est parfois présenté comme une espèce relevant d'un genre plus vaste (qui comprendrait par ailleurs l'asile extra-territorial dans ses variantes traditionnelles: asile "diplomatique" et asile "maritime"). Dans certaines législations 35 et de manière assez malencontreuse, la formule de l'asile "territorial" paraît être isolée des autres modalités de l'asile (lato sensu) et s'appliquer à des étrangers dont la situation mérite une attention particulière (personnes auxquelles la qualité de réfugié a été refusée, personnes exposées à des traitements contraires à l'article 3 de la Convention européenne de sauvegarde des droits de l'homme et des libertés fondamentales dans leur pays d'origine, ou dont la vie et la liberté y seraient menacées). ${ }^{36}$ Mais on peut ne pas être convaincu du bien-fondé de tels clivages. ${ }^{37}$

C'est vraisemblablement en raison de la place privilégiée de l'État dans la conception et la mise en oeuvre du droit d'asile que celui-ci pré-

35 Tel est le cas de la loi française no. 98-349 du 11 mai 1998 relative à l'entrée et au séjour des étrangers en France et au droit d'asile, JO 12 mai, p. 7087; v. F. Luchaire, "La loi relative à l'entrée et au séjour des étrangers et au droit d'asile devant le Conseil constitutionnel", $R D$. publ., 1998, p. 1015; D. Turpin, "La loi, no. 98-349 du 11 mai 1998, relative à l'entrée et au séjour des étrangers en France et au droit d'asile", $R G d r$. int. pr. 1998, no. 87, p. 521 et s.; C. Teitgen-Colly et F. Julien-Laferrière, "Loi no. 98-349 du 11 mai 1998 relative à l'entrée et au séjour des étrangers et au droit d'asile", AJDA, 1998, p. 922 et s.; p. 1001 et s.

36 V. les articles 31 et 36 de la loi du 11 mai 1998, précitée.

37 On pourrait soutenir par exemple que toutes les formes d'asile présentent un aspect territorial puisque l'asile évoque un lieu de refuge. 
sente un caractère éminemment politique. ${ }^{38}$ Le terme figure parfois expressément dans les textes constitutionnels ou législatifs. ${ }^{39}$ En toute hypothèse, la dimension politique de l'asile résulte simplement du fait qu'il se présente aujourd'hui comme une prérogative de l'État —et qu'il affecte (directement ou indirectement) les relations entre l'État d'accueil et l'État d'origine-. Aucune autre collectivité publique, aucune communauté civile ou religieuse, a fortiori aucun individu ne peut s'attribuer un tel pouvoir.

Dans l'analyse des situations susceptibles de justifier une demande d" "asile" (soit au titre de la Constitution, soit au titre d'une convention internationale), le comportement des autorités publiques du pays de provenance est dès lors la première donnée prise en compte au regard de celui des demandeurs eux-mêmes. Dans les Etats qui ont conféré au droit d'asile la portée officielle d'un droit subjectif, l'action en faveur de la liberté (France), associée parfois à d'autres idéaux (Portugal), ou au moins la possibilité d'exercer effectivement les libertés démocratiques correspondant à une certaine conception de l'État de droit (Italie) constituent les seuls motifs officiels susceptibles d'être retenus par les autorités de l'État d'accueil.

Même si l'on sait qu'en pratique les choses ne sont pas toujours aussi claires, et si les mobiles qui conduisent à la quête d'un asile ne sont pas forcément des mobiles politiques, l'interprétation des comportements des autorités publiques du pays d'origine (participation active aux persécutions, tolérance ou inertie volontaire devant les persécutions privées) a inévitablement politisé le débat. ${ }^{40}$

Dès lors, le problème du droit d'asile s'insère dans une politique plus vaste, celle de l'immigration, ${ }^{41}$ dont il devient un élément parmi d'autres.

38 Ph. Ségur, op. cit., p. 96 et s.

39 Ainsi en Allemagne (Loi fondamentale, article 16, a: "Les persécutés politiques...").

40 V. par ex., en ce qui concerne les réfugiés, la motivation de l'arrêt du Conseil d'État du 27 avril 1998, Beltaifa, Req. no. 168.335: dans le cas où les activités du demandeur d'asile conventionnel "même dépourvues de mobile politique, sont regardées par les autorités du pays comme une manifestation d'opposition politique susceptible d'entraîner des persécutions, elles peuvent, le cas échéant, ouvrir droit à la reconnaissance de la qualité de réfugié".

41 On peut se référer, pour la France, à P. Weil, La France et ses étrangers. L'aventure d'une politique de l'immigration 1938-1991, Calmann-Levy, Paris, 1991; P. Weil, Mission d'étude des législations de la nationalité et de l'immigration, Doc. Franç., Paris, Collections des rapports officiels, 1997; F. Moderne, V “Immigration”, in Répertoire de droit international, Dalloz, Paris, 1998. 
L'utilisation dévoyée des procédures d'asile par les immigrants économiques a contribué à accélérer un processus déjà très avancé.

A cette évolution, qui n'est pas propre aux démocraties européennes, s'ajoutent des dérives plus conjoncturelles à l'époque contemporaine.

\section{LES DÉRIVES CONTEMPORAINES: REJET ET INTERNATIONALISATION}

L'analyse des données du droit d'asile est fortement perturbée depuis quelques décennies par des comportements nationaux ou internationaux qui en altèrent sensiblement la signification originaire. Le constat est aisé, et général. Les causes en sont connues, et recensées. Il suffira donc de resituer le débat dans une problématique d'ensemble, dont les éléments sont d'ordre interne et d'ordre international.

Du côté des Etats eux-mêmes, ce sont des comportements de rejet ou de refus qui prédominent, sous une forme ou une autre. Du côté du droit international, c'est à une absorption programmée du droit d'asile par des instruments qui n'ont pas cette vocation que procède l'Europe d'aujourd'hui.

\section{A. Les comportements nationaux: un rejet manifeste ou latent}

On peut les désigner ainsi, semble-t-il, dans la mesure où ils présentent des traits communs dans tous les pays du champ de recherche et où ils traduisent de manière explicite ou larvée le refus de faire produire au droit d'asile les effets qui pourraient —et devraient— être les siens sous l'angle juridique. Quelles que soient leurs motivations (sociologiques, économiques, sociales, politiques, psychologiques ou autres), le juriste ne peut qu'enregistrer les distorsions qui s'accusent entre le concept de droit d'asile et la réalité de ce droit.

Les défaillances des pouvoirs constituants, et constitués, s'ajoutent ici aux pratiques restrictives sur le terrain. Quel que soit le titre invoqué par le demandeur d'asile, les obstacles à franchir pour y accéder se sont multipliés. Les ouvrages mentionnés supra en donnent des témoignages éloquents, que corroborent d'autres analyses, et qui justifient les inquiétudes manifestées par les instances internationales ou les organisations humanitaires. Il est inutile d'en reprendre l'examen: qu'il s'agisse des amendes infligées aux transporteurs qui ne contrôleraient pas avec vigi- 
lance la validité des documents de voyage, du placement dans les zones d'attente aux frontières, du maniement abusif des notions de "pays d'origine sûrs", de "pays de transit sûrs" ou de "demandes d'asile manifestement infondées", de l'examen expéditif des dossiers par des autorités insuffisamment qualifiées pour traiter ces questions délicates, de l'absence ou de l'inefficacité calculée des voies de recours, des procédures de "reconduite à la frontière" ou d'expulsion accélérées, la liste des méthodes dissuasives s'allonge objectivement et inexorablement au-delà des discours politiques et des bonnes intentions parfois officiellement affichées. ${ }^{42}$ Les demandeurs d'asile authentiques ou ceux qui invoquent les dispositions de la Convention de Genève sont a priori tous suspects de vouloir entrer illégitimement dans les Etats de la vieille Europe et celle-ci réagit par anticipation en se constituant, selon l'image consacrée, en "forteresse" bardée de défenses.

Peu importent encore une fois les raisons profondes de cette attitude de repli: il suffit d'observer qu'elle est générale, qu'elle atteint les pays naguère les plus accueillants et qu'elle se traduit pratiquement par les mêmes mesures, avec des habillages plus ou moins sophistiqués destinés à les rendre plus présentables. Le droit d'asile proprement dit se dilue dans les politiques globales de traitement des demandes déposées au titre de la Convention de Genève et, plus largement encore, dans les politiques nationales d'immigration.

Cette situation est le résultat d'une conjonction de facteurs dont les effets se combinent ou se superposent de manière plus ou moins perverse.

En dehors des "non-dits" des réformes, qui relèvent plutôt de la psychologie des gouvernants, ${ }^{43}$ ou des interprétations abusives des textes

42 On songe bien entendu, aux dernières réformes introduites en la matière par la loi française no. 98-349 du 11 mai 1998 qui a modifié pour la $\mathrm{n}^{\text {ème }}$ fois la vieille ordonnance du 2 novembre 1945 relative aux conditions d'entrée et de séjour des étrangers en France (JO, 12 mai 1998, p. 7087). L'accueil a été pour le moins mitigé (v. les études de D. Turpin, “La loi no. 98-349 du 11 mai 1998 relative à l'entrée et au séjour des étrangers en France et au droit d'asile; de la Rose (les promesses socialistes d'abrogation des lois Pasqua et Debré) à la R.E.S.E.D.A.”, Rev. crit. dr. int priv., 1998, p. 521 et s.; de C. Teitgen-Colly et F. Julien-Laferrière, "Loi no. 98-349 du 11 mai 1998 relative à l'entrée et au séjour des étrangers en France et au droit d'asile”, AJDA, 1998, p. 922 et s.; p. 1001 et s.; de F. Luchaire, "La loi relative à l'entrée et au séjour des étrangers et au droit d'asile devant le Conseil constitutionnel”, RD. publ., 1998, p. 1015 et s.; d'A. Pena-Gaïa, obs. sous la décision no. 98-399 DC du Conseil constitutionnel du 5 mai 1998, RFDC, 1998, no. 35, p. 634).

43 V. par ex. N. Catala, "Droit d'asile: les non-dits d'une réforme”, Le Monde, 28 nov. 1997. 
(qui relèvent plutôt de celle des autorités de police ou des juges), les déficiences se situent à plusieurs niveaux.

\section{Le silence des constituants}

On rappellera d'abord qu'un nombre très réduit d'Etats se sont aventurés sur le terrain de la reconnaissance constitutionnelle d'un droit d'asile digne de ce nom (quitte à l'encadrer par des conditions légales plus ou moins strictes). On s'est déjà exprimé sur ce point (v. supra). Il faut ajouter que très rares sont les Constitutions de la dernière décennie qui, dans l'Europe centrale et orientale ex-communiste, ont promu le droit d'asile au rang de droit constitutionnel ${ }^{44}$ —et plus rares encore celles qui lui ont réservé une protection spécifique, en dépit de formulations théoriques parfois généreuses-.

Mais la même observation concerne celles des Constitutions où le droit d'asile, bien que proclamé officiellement, n'a pas reçu le moindre contenu substantiel et se trouve au surplus dépourvu de toute garantie. La Constitution espagnole ou celle de la République de Roumanie pourraient servir d'illustrations à ce type de situation.

Et que dire de la réforme constitutionnelle du 28 juin 1993, en Allemagne fédérale $?^{45}$ Si l'article 16-2 n'a pas été abrogé (il reconnaissait aux "persécutés politiques" un droit subjectif d'asile, protégé par le juge

44 V. Constitution de la République de Roumanie du 8 déc. 1991 (article 18, al. 2: "Le droit d'asile est accordé et retiré dans les conditions fixées par la loi...”); Constitution de la République de Bulgarie du 12 juill. 1991 (article 27: "La République de Bulgarie accorde l'asile aux étrangers poursuivis pour leurs convictions ou pour leur activité de défense des droits et libertés internationalement reconnus"); Constitution de la République de Croatie du 22 déc. 1990 (article 33: "Les citoyens étrangers et les apatrides peuvent obtenir l'asile en République de Croatie sauf s'ils sont poursuivis pour des crimes n'ayant pas une nature politique et pour des activités contraires aux principes fondamentaux du droit international”); Constitution de la République de Macédoine du 17 nov. 1991 (article 29-2: "La République garantit le droit d'asile aux étrangers et apatrides poursuivis pour leurs convictions et actions politiques démocratiques") ( v. Constitutions d'Europe centrale, orientale et balte (sous la direction de M. Lesage, Doc. franç. 1995).

45 Bundesgesetzblatt 1993.I, p. 1002; sur cette réforme, v. en langue française, R. Arnold, "La réforme du droit d'asile en Allemagne", RFDA, 1994, p. 276; U. Becker, "Le droit d'asile en Allemagne après la réforme", RFDA, 1998, p. 258; Chr. Tomuschat, "Droit international de l'asile et des réfugiés. Pratique allemande", in Droit d'asile et des réfugiés, Pédone, Paris, 1997; W. Zimmer, "La réforme constitutionnelle du droit d'asile en République fédérale d'Allemagne: la porte étroite", RFDC, 1994, p. 611; F. Moderne, op. cit., p. 37 et s. et la bibliographie citée, note 45; T. Ablard, Le droit d'asile en Allemagne, en France et au Royaume-Uni, étude comparative, Thèse droit, Paris I, vol. I, p. 322 et s. 
constitutionnel), il a été privé de l'essentiel de sa force opératoire par les obstacles de toutes sortes placés sur le chemin du demandeur d'asile. Par le jeu combiné des concepts de pays d'origine sûrs et de pays de transit sûrs, les nouvelles dispositions de l'article 16 a ont établi des barrages efficaces propres à le dissuader. La substance du droit d'asile n'est pas théoriquement atteinte mais le nombre des demandeurs potentiels a été réduit de manière drastique. ${ }^{46}$ Naguère pionnier d'une conception généreuse du droit constitutionnel d'asile, fondée sur la notion de dignité humaine qui constitue un concept-clé pour la lecture de la Loi fondamentale de 1949,

l'Allemagne est rentrée dans cette normalité un peu grise des pays européens qui, tous, voient aujourd'hui l'afflux de demandeurs d'asile davantage comme un fardeau que comme un enrichissement de leurs sociétés... C'est un adieu à un rêve de justice qui a donc été prononcé en $1993 .^{47}$

On ne saurait mieux dire.

\section{Les réticences du législateur}

Les Parlements nationaux ont largement ignoré le droit d'asile lorsqu'il était consacré, ou l'ont assorti de conditions sévères lorsqu'ils disposaient d'un chèque en blanc du pouvoir constituant.

Prenons l'exemple de la France. Aucune loi, jusqu'en 1998 (plus de cinquante ans après la Constitution de 1946 !) n'avait été promulguée pour définir le régime du droit d'asile de l'alinéa 4 du Préambule constitutionnel. Le législateur de 1998 a choisi d'exhumer tant bien que mal la vieille loi du 25 juillet 1952 qui avait un autre objet ${ }^{48}$ et de l'intituler désormais "loi relative au droit d'asile". Elle est donc raccrochée sans excès de précaution à un support qui ne lui était pas a priori destiné. $\mathrm{Au}$ surplus, elle ne régit pas toutes les demandes d'asile et elle exclut par exemple celles qui sont formulées à l'étranger ou aux frontières. Aupa-

46 V. les observations désabusées de Chr. Tomuschat, op. cit., p. 323; d'U. Becker, op. cit., p. 274.

47 Chr. Tomuschat, op. cit., p. 323.

48 Cette loi portait création de l'Office français de protection des réfugiés et des apatrides (OFPRA), dans le cadre de la Convention de Genève sur le statut de réfugié du 28 juillet 1951. Elle se situait donc dans le contexte de l'asile dit "conventionnel", non dans celui de l'asile constitutionnel. 
ravant, un chapitre VII sur "les demandeurs d'asile" avait été introduit (en 1993) dans l'ordonnance du 2 novembre 1945 mais il ne concernait pas les demandes d'asile constitutionnel et, au surplus, ne traitait que la situation des étrangers déjà présents sur le territoire français. ${ }^{49}$

Si l'on se tourne du côté de l'Allemagne, le tableau n'est différent qu'en apparence. Certes des lois ont été prises dans le cadre de l'ancien article 16-2 de la Constitution (aujourd'hui article 16, a, 1), ${ }^{50}$ et elles ont été fréquemment modifiées. Mais les versions successives de la législation sur le droit d'asile, et notamment les modifications intervenues en 1993, à la suite de la réforme constitutionnelle portant sur l'article 16 de la Loi fondamentale, révèlent un amenuisement constant et progressif des garanties offertes aux demandeurs d'asile. La liste législative des pays tiers "sûrs", capables de constituer des filtres efficaces aux demandes d'asile, comporte tous les Etats entourant l'Allemagne, confortant ainsi l'image du "cordon sanitaire" qui a aussitôt été utilisée par les commentateurs. Quant à la première liste des pays d'origine sûrs, elle avait provoqué un certain étonnement outre-Rhin en incluant par exemple le Ghana... On conçoit qu' un auteur ait pu écrire qu' "en déterminant de la sorte ce qu'il reste de la garantie du droit d'asile, le législateur a atteint les limites de ce que l'on peut encore appeler l'État de droit".${ }^{51}$ L'appréciation est sévère. Est-elle pour autant imméritée?

Un coup d'oeil sur la législation italienne montre que l'état des lieux est, en définitive, comparable. Alors que la Constitution du 27 décembre 1947 (article 10, al. 3) renvoyait au législateur le soin de préciser les conditions dans lesquelles les étrangers privés de l'exercice effectif des libertés démocratiques dans leur propre pays pourraient solliciter l'asile sur le territoire de la République italienne, aucun dispositif législatif répondant clairement à cette exigence constitutionnelle n'a été mis en place, jusqu'à aujourd'hui. ${ }^{52}$ Des nomes éparses, composées de lois fragmentaires, de décrets-lois (au sens italien de l'expression) ultérieurement validés ou "réitérés" dans des conditions de constitutionnalité douteuse,

49 Le dispositif a été réinséré dans la loi du 25 juillet 1952, précitée, par la loi du 11 mai 1998 (article 34).

50 Loi du 28 avr. 1965, loi du 16 juill. 1982, loi du 27 juill. 1993 (Bundesgesetzblatt, 5 août 1993, p. 1361).

51 U. Becker, op. cit., p. 274.

52 V. not. B. Nascimbene, "Droit international de l'asile et des réfugiés: pratique italienne", in Droit d'asile et des réfugiés, op. cit., p. 349 et s., et la bibliographie citée, note 210. 
répondaient aux urgences du moment. Un projet de loi "organique" (ici encore au sens italien du terme) a été déposé le 13 mai 1997; mais son examen se déroule avec une lenteur qui ne correspond guère à la volonté d'adhésion du pays aux mécanismes de coopération interétatique nés du système Schengen. ${ }^{53}$ Au demeurant le projet de loi dont il s'agit a intégré pratiquement toutes les mesures restrictives du droit d'asile ou de l'accès au bénéfice de la Convention de Genève déjà en vigueur en Italie ou dans les autres Etats de l'Union européenne. ${ }^{54} \mathrm{~S}$ 'il est voté définitivement dans cette version, le droit d'asile sera banalisé à partir de critères minimum.

L'Espagne ne fait pas exception. Si la Constitution de 1978 (article 13-4) avait confié à la loi la détermination du contenu et du régime du droit d'asile, très discrètement reconnu et très faiblement garanti, le législateur s'était trouvé manifestement embarrassé. Une première loi du 26 mars $1984^{55}$ avait toutefois amorcé une distinction intéressante (et juridiquement correcte) entre la demande d'asile et la demande de statut de réfugié. Par ailleurs elle avait développé une conception libérale du droit d'asile, qui recevait ainsi (pour la première fois dans un pays européen, semble-t-il) un statut législatif relativement protecteur.

Mais ce même texte rejetait en définitive l'évolution possible vers une plus grande subjectivisation du droit d'asile (qui eût été concevable dans un pays qui fut pendant des siècles terre d'émigration): son article 2 n'hésitait pas à affirmer que l'asile était concédé par l'État dans l'exercice de sa souveraineté et selon des critères qu'il appréciait discrétionnairement. Au demeurant, un obstacle majeur, l'absence de recours d'amparo (v. supra), paralysait les interprétations les plus optimistes. En toute hypothèse, une seconde loi, du 19 mai $1994,{ }^{56}$ a opéré un revirement

53 Le Sénat italien a adopté le 5 novembre 1998 le projet de loi relatif aux normes en matière de protection humanitaire et de droit d'asile.

54 Par exemple sur les notions de pays tiers "sûr", de demande "manifestement infondée", et caetera. Par ailleurs, il n'est pas prévu que le droit d'asile constitutionnel bénéficie d'un régime différent de celui qui est déterminé pour l'application de la Convention de Genève, ce qui réduit déjà l'intérêt théorique de la réforme en cours.

55 Loi no. 5-1984 du 26 mars 1984 portant réglementation du droit d'asile et de la condition du réfugié; v. M.L. Espada Ramos et M. Moya Escudero, "La ley reguladora de asilo y condición del refugiado de 26 de marzo de 1984: nacionalismo o internacionalismo?", Revista de estudios internacionales, 1985, vol. V, no. 1, p. 82 et s.; F. Moderne, "Note sur les problèmes posés par les immigrés et les réfugiés dans l'Espagne contemporaine”, in Immigrés et réfugiés dans les démocraties occidentales, Economica, 1988, p. 79 et s.

56 Loi no. 9/94 du 19 mai 1994, BOE, 23 mai, p. 15796. 
sensible par rapport aux conceptions initiales. La distinction entre demandeur d'asile et réfugié était abandonnée sans explication; le droit d'asile se résumait au droit de demander l'asile ${ }^{57}$ selon les règles et dans les conditions établies par la Convention de Genève. L'assimilation ainsi consacrée par la loi ${ }^{58} \mathrm{~s}$ 'accompagnait d'un durcissement des procédures d'accueil. Il est vrai que l'Espagne, comme l'Italie, a adhéré à l'Accord de Schengen et aux conventions qui ont suivi, dont les exigences se seraient sans doute mal accomodées du libéralisme du texte de 1984.

Quant à la législation portugaise, pour prendre un dernier exemple, elle illustre d'autant mieux la distance qui s'est instituée entre les proclamations constitutionnelles du droit d'asile et leurs traductions législatives que la Constitution du 2 avril 1976 avait adopté de ce droit une conception particulièrement ouverte et libérale. La loi du 29 septembre 1993, qui régit aujourd'hui la matière, a choisi en revanche une approche tellement réductrice que sa constitutionnalité a été mise immédiatement en doute: ${ }^{59}$ les possibilités de rejet des demandes d'asile prévues par ce texte sont en effet pratiquement indéterminées.

La palette des Etats européens dont les lois nationales s'avèrent être davantage des instruments de défense contre l'accès des demandeurs d'asile que des instruments d'accueil de personnes en quête de refuge ne se limite pas aux exemples qui viennent d'être donnés. Mais ceux-ci sont d'autant plus significatifs que les textes constitutionnels offraient apparemment d'autres perspectives. ${ }^{60}$

57 Malgré les efforts faits par une partie de la doctrine pour préserver l'interprétation subjective du droit d'asile (en ce sens D. Blanquer, Asilo político en España, Civitas, Madrid, 1997).

58 Elle correspondait déjà à la pratique suivie par les autorités publiques dans le cadre de la loi de 1984.

59 Vital Moreira, "O direito de asilo entre a Constituiço e a lei", in $O$ asilo em Portugal, op. cit., p. 73 et s.; M. J. de Araújo Torrès, Préface à Direito do Estrangeiros, Ed. Cosmos, Lisbonne, 1995 , p. 23.

60 Il faudrait d'ailleurs rapprocher les politiques législatives de l'asile et les conceptions étatiques en matière de droit de la nationalité. Elles ne sont pas sans relations. J. Habermas a ainsi souligné que les déficiences dans la gestion du problème de l'immigration en Allemagne (dont le droit constitutionnel d'asile est une des données de base) étaient liées à une conception de l'identité collective des Allemands centrée sur la culture et le langage (J. Habermas, L'intégration républicaine. Essai de théorie politique, Fayard, 1998, p. 240 et s.). 


\section{La défaillance des juges}

Les juges nationaux, juges constitutionnels comme juges ordinaires, ont contribué à réduire les potentialités du droit d'asile dans la grande majorité des Etats européens concernés par le problème.

Certains n'ont pas véritablement pris en compte la dimension de ce droit, soit parce la question ne leur a pas été concrètement posée de manière à définir une politique jurisprudentielle, soit parce que le législateur lui-même évitait de se prononcer sur un thème sensible et ne donnait pas prise à un traitement jurisprudentiel cohérent.

D'autres ont des responsabilités plus directes dans l'état actuel du droit d'asile.

La validation par le juge constitutionnel allemand des réformes législatives introduites en 1993 à la suite d'une révision de la Loi fondamentale (v. supra) a suscité des réactions parfois indignées chez les commentateurs.

Lisons à ce sujet J. Habermas: ${ }^{61}$ "Par une justification scandaleuse du point de vue du droit constitutionnel, le deuxième sénat de la Cour constitutionnelle fédérale a déclaré, le 14 mai 1996, conforme à la Constitution la réglementation concernant les "Etats tiers" prévue par la nouvelle version du droit fondamental à l'asile politique, ainsi que la réglementation concernant la définition des "pays d'origine offrant toute sécurité". Un droit fondamental s'efface ainsi au profit d'impératifs fonctionnels qui appellent un refoulement rapide". ${ }^{6}$

Le Tribunal constitutionnel espagnol est-il à l'abri de la critique lorsque, saisi d'un recours en inconstitutionnalité contre la nouvelle loi sur l'asile du 19 mai 1994 modifiant dans un sens nettement restrictif la loi du 26 mars 1984, il fait attendre plusieurs années sa décision qui n'était pas encore rendue à la fin de l'année 1998? Pendant ce temps, et en toute impunité, les mesures les plus contestées s'appliquent aux candidats à l'asile (détention provisoire pendant la durée d'examen de leurs dossiers, fixation d'un numerus clausus au-delà duquel le contrôle se fait plus strict, amoindrissement des protections juridictionnelles, et caetera).

61 L'intégration républicaine, op. cit., p. 238, note 1.

62 V. aussi H. Prand (Süddeutsche Zeitung, 15-16 mai 1996): “Aux yeux de la Cour constitutionnelle, le refoulement rapide compte plus que... le droit d'asile, plus que la dignité humaine, plus que le principe d'une procédure équitable". 
Le Conseil constitutionnel français, lui-même, s'il a eu un sursaut en 1993, s'était jusque là borné à entériner l'interprétation délibérément réductrice du Conseil d'État et avait refusé de faire produire un effet direct aux dispositions de l'alinéa 4 du Préambule de 1946, estimant que l'exercice de ce droit passait par des lois internes (qui n'existaient pas) ${ }^{63}$ et des conventions internationales (qui avaient un autre objet).

Que le juge constitutionnel soit considéré aujourd'hui comme le protecteur attitré des droits fondamentaux fait figure de dogme. Que la Constitution comme norme soit la référence obligée d'un tel contrôle ne paraît pas davantage prêter à contestation. Il reste que si la norme est déficiente ou ambiguë et si le juge faillit à sa mission, le problème n'est pas réglé. Les ressources de la "raison" sont manipulables dans les enceintes judiciaires comme dans les enceintes politiques. Et derrière la ratio legis prétendument retrouvée se dissimuleront éventuellement les formes plus ou moins larvées de l'arbitraire. La normativité, ici comme ailleurs, n'aura qu'une vertu méthodologique ou celle d'une technique de camouflage.

\section{B. La tentation de l'amalgame: sur l'internationalisation du droit d'asile}

Une seconde dérive caractérise l'évolution du droit d'asile depuis qu'il a été mis en forme dans le contexte de l'après-guerre. La dimension internationale de ce droit l'emporte nettement sur sa dimension interne. L'asile a toujours concerné, on l'a dit, les relations entre Etats. Le paradoxe contemporain vient de ce qu'il n'a pas été traité en tant que tel par voie de convention internationale, alors que les conventions internationales qui n'avaient pas cet objet sont regardées aujourd'hui, dans le langage courant et même dans le langage officiel, comme relatives au droit d'asile. C'est bien entendu la Convention de Genève du 28 juillet 1951 sur le statut de réfugié qui est à l'origine de cette confusion, soigneusement entretenue jusque dans les derniers développements du droit communautaire liés à l'adoption du Traité d'Amsterdam. Les juges et les législateurs nationaux se sont prêtés complaisamment à ce jeu de miroirs.

63 Les premières mesures législatives ayant trait spécifiquement aux demandeurs d'asile datent de 1993; mais elles sont loin de répondre aux données du problème (v. supra); il faudra attendre la loi "Chevènement" de 1998 pour que le droit d'asile soit retiré de la législation sur les étrangers et traité en tant que tel (sur un mauvais support, il est vrai) (v. sur la question, F. Moderne, Le droit constitutionnel d'asile dans les Etats de l'Union européenne, op. cit., p. 41 et s.). 


\section{La captation du droit d'asile par le droit international conventionnel}

a) La Convention de Genève de 1951, faut-il le rappeler, ne traite que du statut de réfugié et n'entend pas internationaliser le droit d'asile. Elle n'aborde ce droit (sans d'ailleurs le désigner nommément) qu'à travers quelques (rares) dispositions dont les plus connues sont le principe de non-refoulement vers l'État d'origine des candidats au statut de réfugié dont la vie ou la liberté seraient menacées en raison de leur race, de leur nationalité, de leur religion, de leur appartenance à un groupe social ou de leurs opinions politiques (article 33$)^{64}$ ou le principe d'interdiction des sanctions pénales ou administratives à l'encontre des demandeurs démunis de titres réguliers de voyage et de séjour (article 31-1).

Cette omission n'est nullement accidentelle. On a rappelé ci-avant que la lacune n'avait pu être comblée par une nouvelle Conférence internationale des Nations Unies réunie précisément à cet effet en 1977.

Par ailleurs, ainsi qu' on l'a dit, la Convention de Rome du 4 novembre 1950 sur la sauvegarde des droits et des libertés fondamentales, dont le champ est réduit aux pays membres du Conseil de l'Europe et qui a fait l'objet de discussions parallèles à celles qui ont précédé la Convention de Genève, ne fait aucune mention du droit d'asile, lequel n'est donc pas regardé comme une liberté fondamentale dans le cadre géographique qui, pourtant, s'y prêtait le mieux. Aucun des Protocoles qui suivirent n'a jugé nécessaire de compléter la Convention européenne sur ce point.

Comment la Convention de Genève est-elle devenue le symbole du droit d'asile (dit "conventionnel"), ${ }^{65}$ après qu'elle l'ait exclu délibérément de son champ d'application? C'est là un paradoxe supplémentaire dans une matière qui n'en avait nul besoin.

En termes de droit international, la Convention de 1951 ne porte que sur le statut de réfugié. Certes, les relations entre la notion de "réfugié" et le droit d'asile ne peuvent être complètement ignorées ni écartées. La qualité de réfugié ne comporte pas comme corollaire nécessaire le droit d'asile sur le territoire d'accueil mais elle ne l'interdit pas non plus. ${ }^{66}$ On

64 W. Kälin, Das Prinzip des Non-Refoulement, Berne, 1982; v. sur l'ensemble du problème, Droit d'asile et des réfugiés (Colloque de la Société française pour le droit international), Pedone, 1997.

65 H. Labayle, "Le droit d'asile en France: normalisation ou neutralisation?", RFDA, 1997, p. 242 et s., not. p. 245 et s.

66 On se référera sur ces points à l'analyse de D. Alland, "Le dispositif international du droit de l'asile", in Droit d'asile et des réfugiés, op. cit., not. p. 62 et s. 
doit même admettre qu'il est difficile pour un État de statuer sur une demande d'application de la Convention de Genève sans accorder ne serait-ce que provisoirement, l'asile au demandeur. ${ }^{67}$ On voit tout aussi bien que lorsque la qualité de réfugié est reconnue (elle a un caractère rétroactif), la conséquence normale est l'octroi de l'asile à l'intéressé sous forme d'un permis de séjour sur le territoire de l'État d'accueil.

Mais ces observations doivent être relativisées.

Du côté des demandeurs d'asile "conventionnel", au titre de la Convention de Genève, il n'y a pas de lien absolu entre l'existence de facto d'un droit d'asile et le bénéfice du statut de réfugié. Non seulement tous les demandeurs d'asile ne cherchent pas pour autant à obtenir le statut de réfugié, mais il va sans dire que ceux qui le demandent ne l'obtiendront pas nécessairement, ce qui pose inéluctablement le difficile problème de la présence sur le territoire national des "déboutés" de l'accès au statut.

Du côté de l'État d'accueil, rien dans la Convention de Genève ne le contraint à autre chose que de ne pas remettre l'étranger qui sollicite la qualité de réfugié aux autorités de son pays d'origine ${ }^{68}$ —et, bien entendu, de ne pas le punir-. Il appartient au droit interne de décider si l'asile territorial doit ou non accompagner l'octroi du statut (ce qui est logiquement le cas); mais les Etats n'ont contracté aucun engagement à cet égard sur le plan international.

Une autre raison de la confusion qui s'est instituée dans le vocabulaire du droit de l'asile est due tout simplement à la rédaction de la Convention de 1951 elle-même: celle-ci emploie le terme "réfugié" (au sens de l'article $1^{\text {er }}$ ) à la fois pour ceux qui ont obtenu effectivement le statut qu'elle organise et pour ceux qui ne l'ont pas encore obtenu (et qui n'y ont pas nécessairement droit).

67 Tel est le sens des arrêts d'Assemblée du Conseil d'État français du 13 décembre 1991, Dakoury et Nkodia, Rec. CE, p. 439 et 441, concl. R. Abraham; RFDA 1992, p. 90, concl. R. Abraham; AJDA 1992, p. 114, chron. Ch. Maugüé et R. Schwartz; D. 1992, p. 447, note F. JulienLaferrière: l'étranger qui sollicite la qualité de réfugié doit être "en principe autorisé à demeurer provisoirement sur le territoire jusqu'à ce qu'il ait été statué sur sa demande". Cette solution n'est pas, selon toute vraisemblance, sans avoir influé sur la célèbre décision du Conseil constitutionnel du 13 août 1993, précitée.

68 Rappelons que le Conseil d'État en a fait un principe général du droit applicable aux réfugiés (CE, Ass. $1^{\text {er }}$ avr. 1988, Bereciartua-Echarri, Rec. CE, p. 135; Grands arrêts du Conseil d'État, no. 111, p. 727, obs. de MM. Long, Weil, Braibant, Delvolvé et Genevois et les références citées. 
Seuls quelques Etats ont fait l'effort de mieux séparer les qualités de demandeur d'asile et de réfugié. ${ }^{69}$

b) L'assimilation qui s'est progressivement opérée entre l'application de la Convention de Genève et le bénéfice du droit d'asile a été entretenue et amplifiée par les accords et conventions qui ont mis en place le dispositif de Schengen. ${ }^{70}$ Si l'Accord de Schengen du 14 juin 1985 luimême ne se référait pas expressément à la Convention de Genève, il n'en va pas de même des conventions signées pour sa mise en ouvre. La Convention d'application de l'Accord de Schengen du 19 juin 1990 précise que le texte ne s'applique que "sous réserve" de la Convention de Genève. Son article 28 réaffirme l'allégeance des signataires à la Convention matrice de 1951. L'ensemble du texte porte sur le traitement des demandes d'asile dont la définition, donnée à l'article $1^{\text {er }}$, ne laisse aucun doute sur la volonté des Etats de rattacher la nouvelle organisation d'un espace sécuritaire européen à la Convention de Genève: est regardée comme demande d'asile

toute demande présentée par écrit, oralement ou autrement, par un étranger... en vue d'obtenir sa reconnaissance en qualité de réfugié conformément à la Convention de Genève du 28 juillet 1951 relative au statut des réfugiés telle qu'amendée par le Protocole de New York du 31 janvier 1967. ${ }^{71}$

La même inspiration guide la convention-soeur dite de Dublin, signée le 15 juin 1990 (mais dont l'entrée en vigueur a tardé quelque peu) puisqu'elle porte sur la détermination de l'État responsable d'une "demande d'asile" présentée auprès d'un État-membre des Communautés

69 Par exemple l'Espagne, dans la loi no. 5/84 du 26 mars 1984, préc. (v. L. Martín-Retortillo, "La situation juridique du demandeur d'asile: Espagne", RFDA, 1993, p. 557 et s.) Le législateur utilisait deux vocables différents ("asilado" et "refugiado") pour désigner ceux qui avaient obtenu (provisoirement) le droit d'asile et ceux à qui avait été octroyé le statut de réfugié. Mais cette distinction a été supprimée par la loi no. 9/94 du 19 mai 1994.

70 H. Labayle, étude précitée, RFDA, 1997, not. p. 250 et s. et la bibliographie citée, note 42.

71 V. Les accords de Schengen: abolition des frontières intérieures ou menace pour les libertés publiques? (sous la direction d'A. Pauly), Institut européen d'administration publique, Maastricht, 1993. On rappellera que les Accords de Schengen ont été élaborés en marge de la Communauté européenne, mais que les conventions conclues pour leur mise en ouvre anticipaient sur une intégration dans un pilier "communautaire" qui a été réalisée par le Traité d'Amsterdam en cours de ratification (sous la forme d'un Protocole général intégrant l'acquis de Schengen au Traité sur l’Union européenne) (v. sur ces mécanismes, H. Labayle, “Un espace de liberté, de sécurité et de justice", in Le Traité d'Amsterdam, Dalloz, 1998, p. 105 et s.). 
européennes (ce qui traduit un infléchissement marqué vers lesdites Communautés).

Le Traité de Maastricht (signé le 7 février 1992) prit le relais sans états d'âme particuliers: son article K 1, titre VI, mentionne la "politique d'asile" au titre du "troisième pilier" comme relevant des questions " $d$ 'intérêt commun" pour les membres de l'Union européenne, mais précise que ce problème doit être traité "dans le respect de la Convention de Genève et en tenant compte de la protection accordée par les Etats membres aux personnes persécutées pour des motifs politiques".

Quant au Traité d'Amsterdam (signé le 2 octobre 1997), il accentue l'évolution non seulement en intégrant "l'acquis Schengen" dans un pilier communautarisé mais aussi et surtout en prévoyant, dans son article 63 (CE) (ex article $73 \mathrm{~K}$ ) qu'il appartient au Conseil, pendant une période transitoire de cinq ans après l'entrée en vigueur du Traité, de prendre "des mesures relatives à l'asile, conformes à la Convention de Genève du 28 juillet 1951 et au Protocole du 31 janvier 1967 relatifs au statut des réfugiés ainsi qu' aux autres traités pertinents", dans un certain nombre de domaines ${ }^{72}$ et en vue de "mettre en place progressivement un espace de liberté, de sécurité et de justice".73

Est-il besoin d'épiloguer? On est passé d'une Convention qui ne disait rien sur le droit d'asile à une communautarisation des politiques d'asile au nom de cette Convention...

Par là même le droit d'asile, déjà étatisé et désormais internationalisé, n'a plus grand chose à voir avec un "droit" (individuel ou collectif) des demandeurs d'asile. Il se situe pleinement dans la mouvance des relations entre Etats. Il sera donc tributaire, dans le contexte européen né du Traité d'Amsterdam, des avatars de ces relations.

D'autant que, sur ce terrain, jouent des complicités internes actives.

72 Notamment: critères et mécanismes de détermination de l'État membre responsable de l'examen d'une demande d'asile présentée dans l'un des Etats membres par un ressortissant d'un pays tiers, "normes minimales régissant l'accueil des demandeurs d'asile dans les Etats membres", et caetera. (v. H. Labayle, "Un espace de liberté, de sécurité et de justice”, op. cit., p. 141 et s.; du même auteur: "La libre circulation des personnes dans l'Union européenne, de Schengen à Amsterdam", AJDA, 1997, p. 923 et s.; "Droits fondamentaux et droit européen”, AJDA, 1998, no. spéc. sur Les droits fondamentaux, p. 75 et s.).

73 Il faut y ajouter le Protocole no. 6 sur le droit d'asile pour les ressortissants des Etats membres de l'Union européenne qui répond à une problématique spécifique intéressant les rapports entre ces Etats et a été placé sous le contrôle de la Cour de justice des Communautés européennes. 


\section{Les complicités internes}

On veut dire par là que dans la plupart des Etats européens, le droit d'asile même s'il est susceptible d'une définition interne et d'un traitement spécifique, est de plus en plus ouvertement envisagé à travers le prisme déformant de la Convention de Genève ou pour bon nombre d'entre eux, du dispositif Schengen incorporé dans le droit communautaire (avec certaines réserves) par le Traité d'Amsterdam.

Il faut bien convenir que cette tentation n'est pas nouvelle et qu'elle n'a été combattue que très mollement.

Dans les Etats qui ont inscrit le droit d'asile dans leur Constitution, rares ont été les mesures concrètes de mise en ouvre de ce droit (si l'on met à part la République fédérale d'Allemagne). Il aurait fallu notamment préciser les conditions d'obtention de l'asile constitutionnel, prévoir des procédures d'admission, définir les effets de ce type d'asile, etc.

Lorsque des lois sur l'asile ont été votées, elles ont été, à l'instar des législations des autres pays de l'Union européenne n'ayant pas érigé le droit d'asile en droit constitutionnel, consacrées à la mise en ouvre de la Convention de Genève sur le statut de réfugié. Le demandeur d'asile était en définitive assimilé à celui qui réclamait le bénéfice de la Convention de Genève dans les termes et selon les procédures imaginés pour les réfugiés.

Ainsi, en Espagne, depuis la loi no. 9/94 du 19 mai 1994 modifiant la loi no. 5/84 du 26 mars 1984, "le droit d'asile reconnu par l'article 13-4 de la Constitution est la protection accordée aux étrangers auxquels est reconnue la qualité de réfugié" (article 2) et "la condition de réfugié est reconnue et en conséquence l'asile sera accordé à tout étranger qui remplit les conditions prévues par les conventions internationales ratifiées par l'Espagne, notamment par la Convention de Genève du 28 juillet 1951 sur le statut des réfugiés et par le Protocole de New York du 31 janvier 1967 sur le statut des réfugiés" (article 3).

L'autonomie constitutionnelle du droit d'asile est, de ce fait, condamnée.

Les mêmes observations peuvent être formulées par l'Italie. Dans la dernière version du projet de loi sur "les normes en matière de protection humanitaire et de droit d'asile", ${ }^{74}$ il est dit que "les titulaires du droit

74 Projet voté par le Sénat italien le 5 novembre 1998 (“Norme in materia di protezione umanitaria e di diritto di asilo"). 
d'asile" sont d'une part les étrangers ayant vocation à bénéficier du statut de réfugié au sens de la Convention de Genève et les étrangers qui ne peuvent ou ne veulent se réclamer de la protection de leur pays d'origine dans la mesure où ils y sont effectivement empêchés d'exercer les libertés démocratiques, telles que les garantit la République italienne, et se trouvent exposés à des menaces ou à des restrictions graves de leur liberté personnelle (article 2). Aucune différenciation n'est faite dans le corps du texte, ni quant aux procédures ni quant aux effets de la demande, entre les deux catégories de demandeurs.

La démarche du législateur portugais est identique. La loi du 29 septembre 1993 procède à l'assimilation entre les titulaires du droit constitutionnel d'asile (au sens de l'article 33-6 de la Constitution de 1976) et les étrangers qui remplissent les conditions posées par la Convention de Genève (article 1er.), et se réfère, pour traiter l'ensemble des demandes, à la Convention de Genève et au Protocole de New York.

Dans ces deux derniers pays, par conséquent, la notion de demandeur d'asile couvre aussi bien la définition conventionnelle que la définition constitutionnelle. Le régime procédural et les effets de la demande sont, par commodité, liés à l'application de la Convention de Genève (laquelle, faut-il le rappeler, n'est pas une convention sur l'asile territorial).

La France a suivi une démarche plus compliquée pour un résultat quasi-équivalent.

Dans un premier temps ni le Conseil d'Etat ${ }^{75}$ ni le Conseil constitutionnel n'ont voulu voir dans l'alinéa 4 du Préambule de 1946 l'affirmation d'un droit constitutionnel fondamental d'application directe ou (tout au moins en ce qui concerne le Conseil constitutionnel) ont préféré esquiver le débat. ${ }^{76} \mathrm{Ce}$ droit nécessitait, selon les deux hautes juridictions, une médiation; il était mis en ouvre théoriquement par l'intermédiaire de lois (or, elles n'existaient pas) ou de conventions internationales (en fait, la Convention de Genève). ${ }^{77}$

Lorsque prévalut en 1993 la conception du droit d'asile en tant que droit constitutionnel fondamental, aux côtés du droit de solliciter l'application de la Convention de Genève (décis. no. 93-323 DC du 12-13 août

75 CE 27 sept. 1985, France-Terre d'Asile, Rec. CE, p. 263; JDI 1986, p. 347, note F. JulienLaferrière; D. 1986.IR.278, obs. P. Waquet et F. Julien-Laferrière.

76 Décis. no. 79.109 DC du 9 janv. 1980, Rec. Cons. const., p. 29; décis. no. 86-216 DC du 3 sept. 1986, Rec. Cons. const., p. 135; décis. no. 91-294 DC du 25 juill. 1991, Rec. Cons. const., p. 91.

77 Sur les éléments de la polémique, v. notre ouvrage précité, p. 43 et s. et les références citées. 
1993) ${ }^{78}$ la logique de l'interprétation eût voulu que l'on dissociât plus clairement le droit constitutionnel d' asile et le droit d' asile conventionnel. La révision constitutionnelle immédiatement entreprise pour neutraliser la nouvelle jurisprudence et permettre l'application des accords internationaux négociés relatifs à la mise en place du dispositif Schengen, ${ }^{79}$ brouilla quelque peu les cartes. Non seulement, elle supprimait, pour les demandes d'asile conventionnel, l'obligation constitutionnelle d'examiner en tout état de cause les demandes émanant des "combattants de la liberté" ${ }^{80}$ mais encore elle avait inscrit dans le texte même de la Constitution une nouvelle formulation du droit d'asile reprenant pour partie les termes mêmes du Préambule mais cette fois en attribuant ce droit aux... autorités de la République.

Il fallait donc déterminer quelle était désormais la valeur du Préambule constitutionnel au regard des intentions du constituant. L'alinéa 4 , en effet, n'avait pas été officiellement supprimé. Dans sa décision no. 97389 DC du 22 avril 1997, ${ }^{81}$ le Conseil constitutionnel avait fait de nouveau référence à l'alinéa 4 du Préambule de 1946 comme source d'un droit constitutionnel d'asile, mais l'avait aussitôt rattaché au droit de la Convention de Genève en ce qui concerne les éléments de son régime qui lui étaient soumis pour examen ("la confidentialité des éléments d'information détenus par l'OFPRA relatifs à la personne sollicitant en France la qualité de réfugié est une garantie essentielle du droit d'asile, principe de valeur constitutionnelle qui implique également que les demandeurs du statut de réfugié bénéficient d'une protection particulière"). ${ }^{82}$

L'intervention de la loi no. 98-349 du 11 mai 1998 relative à l'entrée et au séjour des étrangers en France et au droit d'asile modifie-t-elle les

78 Rec. Cons. const., p. 224; Grandes décisions du Conseil constitutionnel, $9^{\text {ème }}$ éd., Dalloz, 1997, no. 46, p. 829 et s., obs. L. Favoreu et L. Philip et les références citées, p. 829 et s.

79 Le problème se situe dans le contexte d'une polémique renouvelée sur la hiérarchie des normes de droit interne et de droit international (s'il a fallu une révision constitutionnelle pour obtenir l'application d'un traité, c'est bien parce que ce traité n'avait pas, en lui-même, une force juridique suffisante pour surmonter l'obstacle constitutionnel) (v. D. Alland, "Consécration d'un paradoxe: primauté du droit interne sur le droit international”, RFDA, 1998, p. 1094 et s.).

80 Ce qui établit que le droit d'asile n'est plus un droit subjectif constitutionnellement garanti si l'État responsable de l'examen de la demande d'asile (au sens où l'entendent les conventions de 1990, précitées) n'est pas la France elle-même.

81 Rec. Cons. const., p. 45.

82 Sur les critiques portées à cette rédaction, v. notre ouvrage précité, p. 61 et s. 
données du raisonnement? ${ }^{83}$ Elle a donné lieu à une nouvelle décision du Conseil constitutionnel ${ }^{84}$ dont on ne saurait dire qu'elle contribue (enfin) à conférer au droit constitutionnel d'asile une autonomie réelle: au contraire, à propos d'une disposition qui contestait la constitutionnalité de la présence d'un représentant du Haut Commissariat pour les Réfugiés au sein de la Commission des recours des réfugiés (instance juridictionnelle d'appel des décisions de l'OFPRA) lorsque la demande était fondée sur l'alinéa 4 du Préambule de 1946 (et ce, au motif qu'il s'agissait d'une juridiction chargée de se prononcer dans le seul cadre du droit interne), le juge constitutionnel répond qu'il n'y a pas là une atteinte suffisante aux "conditions essentielles d'exercice de la souveraineté nationale". Et d'ajouter: "les demandes de reconnaissance de la qualité de réfugié, fondées sur l'article $1^{\text {er }}$ de la Convention de Genève et sur le quatrième alinéa du Préambule de la Constitution de 1946 présentent entre elles un lien étroit", de sorte que même si les fondements juridiques des deux catégories de demandes sont "distinctes" (ce qui conforte en apparence l'autonomie du droit d'asile constitutionnel), "elles requièrent un examen éclairé des mêmes circonstances de fait et tendront... au bénéfice d'une protection identique" et que le législateur était en droit, au nom d'une bonne administration de la justice, d'unifier les procédures et de prévoir une instruction commune. ${ }^{85}$

Il est vrai que la loi elle-même a procédé une assimilation des situations des demandeurs d'“asile", qu'ils se placent sous l'égide de la Con-

83 JO, 12 mai, p. 7087; sur la loi elle-même, v. les études de D. Turpin (Rev. crit. dr. intern. pr. 1998, p. 521 et s.); de C. Teitgen-Colly et F. Laferrière (AJDA, 1998, p. 1001 et s.); de F. Luchaire (RD publ., 1998, p. 1015 et s.); de V. Tchen ("La réforme du droit d'asile: entre rupture et tradition", D. 1999, chron., p. 58 et s.).

84 Décis. no. 98-399 DC du 5 mai 1998, JO, 12 mai, p. 7092; sur cette décision, v., outre les études précitées, les observations de J.E. Schoettl (AJDA, 1998, p. 489) et de A. Pena-Gaïa (RFDC, 1998, no. 35, p. 634 et s.).

85 Sur les nuances et réserves qu'appelle une telle interprétation, v. D. Turpin, op. cit., p. 559 et s.; C. Teitgen-Colly et F. Julien-Laferrière, op. cit., p. 1004; A. Pena-Gaïa, op. cit., p. 639. Il faut ajouter que, derrière l'argumentation avancée, le problème majeur est celui de l'origine de la demande d'asile ou de refuge. Aux termes d'une jurisprudence classique (mais contestée), les instances juridictionnelles chargées de l'application et de l'interprétation des stipulations de la Convention de Genève prennent en compte au premier chef les persécutions organisées (ou du moins encouragées ou tolérées volontairement) par les autorités publiques du pays d'origine, pour octroyer le statut de réfugié. Les dispositions du Préambule, interprétées d'une autre manière puisque ne précisant pas l'origine des persécutions, permettraient d'accueillir plus largement les demandes d'asile. Il est vrai que la politique jurisprudentielle de la Commission des recours des réfugiés est évolutive (v. F. Tiberghien, "Statut de réfugié et persécution par des agents non publics", RFDA, 1998, p. 244 et s.). 
vention de Genève ou qu'ils invoquent l'alinéa 4 du Préambule constitutionnel. C'est là l'objet du nouvel article 2 de la loi du 25 juillet 1952, modifiée:

la qualité de réfugié est reconnue par l'Office à toute personne persécutée en raison de son action en faveur de la liberté ainsi qu'à toute personne sur laquelle le Haut Commissariat des Nations Unies pour les réfugiés exerce son mandat aux termes des articles 6 et 7 de son statut tel qu'adopté par l'Assemblée générale des Nations Unies le 14 décembre 1950 ou qui répond aux définitions de l'article $1^{\text {er }}$ de la Convention de Genève du 28 juillet 1951 relative au statut des réfugiés.

En revanche, il appartiendrait au ministre de l'Intérieur d'accueillir au titre des prérogatives régaliennes réservées par la Constitution (article 53, al. 2) depuis la réforme de 1993 (article 2 de la loi du 25 juill. 1952, in fine) ceux des demandeurs d'asile qui n'auraient pas obtenu la qualité de réfugié. Assez curieusement, l'octroi de cet "asile territorial" par décision ministérielle est subordonné (article 13 L. 25 juill. 1952, modifiée) à la preuve par l'intéressé que sa vie ou sa liberté sont menacées dans son pays ou qu'il y est exposé à des traitements inhumains ou dégradants $^{86}$ — tous éléments qui, a priori, eussent justifié que la qualité de réfugié ne lui soit pas refusée...-.

En toute hypothèse, le rapprochement opéré par le législateur de 1998 entre la demande d'asile constitutionnel et la demande d'asile conventionnel, sous l'égide de la notion de "réfugié", avec intervention de l'OFPRA et, sur recours, de la Commission des recours des réfugiés et du Conseil d'État, contribue à réduire l'autonomie réelle du droit d'asile au sens de l'alinéa 4 du Préambule. Il y a tout lieu d'imaginer que les pratiques procédurales et les appréciations des situations de fait passeront par le même moule, celui de la Convention de Genève.

Le Conseil d'État n'y paraît d'ailleurs pas hostile si on en juge par un arrêt du 3 avril 1996, Traoré ${ }^{-87}$ (selon lequel l'argumentation fondée sur le Préambule constitutionnel ne pouvait fonder des "conclusions distinc-

86 On doit admettre que la décision ministérielle, bien que non motivée (article 13, préc., al. 2), ne constitue pas un acte de gouvernement, mais qu'elle relève d'un pouvoir discrétionnaire. Le contentieux en appartient au juge administratif ordinaire.

87 Rec. CE, p. 113; D. 1997, p. 42, obs. F. Julien-Laferrière; RFDA, 1997, p. 278 (v. aussi Comm. des recours 17 déc. 1993, Traoré, RGDI Publ., 1994, p. 234, note D. Alland). 
tes de celles tendant à obtenir la reconnaissance de la qualité de réfugié mais un moyen à l'appui de ces conclusions").

$$
* * *
$$

L'imbroglio qui s'annonce dans la combinaison des diverses notions ayant reçu un label officiel interne (soit constitutionnel soit législatif) et/ou international (Convention de Genève, conventions européennes) et des recours qui les accompagnent alimentera vraisemblablement une controverse durable.

Ainsi le droit d'asile est-il soumis dans l'Europe contemporaine à rude épreuve. Après l'entrée en vigueur du Traité d'Amsterdam, qui communautarise les questions d'immigration, d'asile et de séjour liées à la libre circulation des personnes, la mise en place du nouveau dispositif et sa gestion quotidienne susciteront des tensions entre les gouvernements et les instances communautaires. Il faudra clarifier les notions utilisées, harmoniser les pratiques administratives et les contrôles juridictionnels (et plus encore sans doute les comportements des agents à tous les niveaux) et déterminer les compétences exactes de la Cour de justice des Communautés européennes. ${ }^{88}$ La récente communication de la Commission des Communautés européennes ${ }^{89}$ évoque la politique d'asile parmi les préoccupations immédiates de l'Union européenne, et préconise de nouveaux instruments internationaux complémentaires de la Convention de Genève. La proposition de décision du Conseil, émanant de la même Commission $^{90}$ analyse largement les mesures destinées "à soutenir concrètement l'accueil et le rapatriement volontaire de réfugiés, de personnes déplacées et de demandeurs d'asile". Il semble que les nouvelles catégories juridiques qui se dessinent entendent séparer plus nettement les notions de "réfugié", de "personne déplacée" 91 et de "demandeur d'asile". Ce der-

88 Sur les restrictions apportées au contrôle juridictionnel de la CJCE sur les questions concernant le maintien de l'ordre public et la sauvegarde de la sécurité intérieure (article 68, ex. $73 \mathrm{P}, \mathrm{du}$ Traité), v. les observations d'H. Labayle in "Un espace de sécurité de justice et de liberté", op. cit., p. 153; "La libre circulation des personnes dans l'Union européenne, de Schengen à Amsterdam", op. cit., AJDA, 1997, p. 923 et s., not. p. 935 et s.

8914 juill. 1998, Com. (1998) 459 final, "Vers un espace de liberté, de sécurité et de justice".

9016 déc. 1998, Com. (1998) 733 final.

91 Le thème des "personnes déplacées" qui ne sont pas destinées à relever du statut de réfugié (au moins dans un premier temps) a pris une ampleur significative au cours des dernières années, 
nier concept s'appliquerait désormais soit aux personnes ayant réclamé le bénéfice du statut de réfugié, avant toute décision des instances compétentes, soit aux personnes qui restent sur le territoire d'un État membre bien que la qualité de réfugié leur ait été refusée.

Le droit d'asile est pour l'instant plutôt malmené dans les Etats de l'Union européenne. Trouvera-t-il une assise juridique plus solide dans le contexte d'Amsterdam? Et à quel prix?

en liaison avec les événements tragiques survenus en ex Yougoslavie (v. J. Tenenbaum, "Vers une protection coordonnée des personnes déplacées au sein de l'Union européenne”, Europe, janv. 1999, p. 5 et s.). La notion de "personne déplacée", qui figure dans plusieurs documents communautaires ou du Conseil de l'Europe, est consacrée par le Traité d'Amsterdam (article 63, ex. 73 K). 